\title{
Management of keloids and hypertrophic scars: current and emerging options
}

This article was published in the following Dove Press journal:

Clinical, Cosmetic and Investigational Dermatology

23 April 2013

Number of times this article has been viewed

\section{Gerd G Gauglitz}

Department of Dermatology and Allergy, Ludwig-Maximilian University, Munich, Germany
Correspondence: Gerd G Gauglitz Department of Dermatology and Allergy, Ludwig-Maximilian University, Frauenlobstr 9-II, 80337 Munich,

Germany

Tel +498951606010

Fax +498951606389

Email gerd.gauglitz@med.uni-muenchen. de

\begin{abstract}
In the context of growing aesthetic awareness, a rising number of patients feel disappointed with their scars and are frequently seeking help for functional and aesthetic improvement. However, excessive scarring following surgery or trauma remains difficult to improve despite a plethora of advocated treatment strategies as frequently observed in daily clinical routine. It is thus still preferable to prevent scarring by minimizing risk factors as much as possible. Hence, it remains crucial for the physician to be aware of basic knowledge of healing mechanisms and skin anatomy, as well as an appreciation of suture material and wound closure techniques to minimize the risk of postoperative scarring. Next to existing, well known prophylactic and therapeutic strategies for the improvement of excessive scarring, this article discusses emerging techniques such as intralesional cryotherapy, intralesional 5-fluorouracil, interferon, and bleomycin. Some of them have been successfully tested in well-designed trials and already have extended or may extend the current spectrum of excessive scar treatment in the near future. Innovative options such as imiquimod 5\% cream, photodynamic therapy, or botulinum toxin A may also be of certain importance; however, the data currently available is too contradictory for definite recommendations.
\end{abstract}

Keywords: intralesional cryotherapy, lasers, triamcinolone acetonide, TGF- $\beta$

\section{Introduction}

Scars form following any insult to the deep dermis as a result of the complex physiologic wound healing cascade which can be temporally grouped into three distinct phases (inflammation, proliferation, and remodeling). ${ }^{1}$ Immediately following wounding, platelet degranulation and activation of the complement and clotting cascades form a fibrin clot for hemostasis, which acts as a scaffold for wound repair. ${ }^{2}$ Platelet degranulation is responsible for the release and activation of an array of potent cytokines and growth factors, which serve as chemotactic agents for the recruitment of macrophages, neutrophils, fibroblasts, and others. ${ }^{2,3}$ Recruited fibroblasts synthesize a scaffold of extracellular matrix (ECM) which builds a structural framework to bridge the wound and allow vascular ingrowth. ${ }^{4}$ Myofibroblasts help initiating wound contraction. Once the wound is closed, the immature scar transitions into the final maturation phase, where abundant ECM is degraded and immature type III collagen is modified into mature type I collagen. ${ }^{4}$ Characteristically, fresh scars appear reddish, sometimes itchy and slightly elevated, eventually turning to flat, frequently depigmented scars without further symptoms, within a period of months. ${ }^{5}$ The majority of scars fade at approximately 7 months as demonstrated recently by examining the natural history of scar redness and maturation after incisional and excisional wounds. ${ }^{6}$ 
Thus, transformation of a wound clot into granulation tissue requires a delicate balance between ECM protein deposition and degradation, and when disrupted, abnormalities in scarring appear. In the past, specific anatomic locations, infection, genetic susceptibility, and delayed epithelialization have been shown to increase the risk of keloid or hypertrophic scar formation after even minor surgical or laser procedures - particularly in predisposed individuals. Both lesions represent aberrations in the fundamental processes of wound healing, where there is an obvious imbalance between the anabolic and catabolic phases. ${ }^{1}$ A scar is densely populated by inflammatory cells, which release fibrogenic factors, such as transforming growth factor (TGF)- $\beta 1$ and $\beta 2$. This environment enhances accumulation of ECM, while its degradation is impaired (via decreased levels of TGF- $\beta 3$ and matrix metalloproteinases [MMP], eg, MMP-9). ${ }^{7}$ Recent evidence suggests that both the severity of inflammation and the type of immune response predisposes to excess scar formation. ${ }^{7}$ Development of a $\mathrm{T}$ helper (Th)-2 response promotes fibrogenesis, whereas a Th-1 predominance attenuates the tissue fibrosis. ${ }^{89}$ The exact molecular basis of pathological scar formation, however, remains partially poorly understood. Keloids appear to be a more sustained and aggressive fibrotic disorder than hypertrophic scars. ${ }^{1}$ Evidence to date strongly implies a more prolonged inflammatory period with immune cell infiltrate present in the scar tissue of keloids, the consequence of which may contribute to increased fibroblast activity with greater and more sustained ECM deposition. ${ }^{7}$ This in turn may help to explain why keloid scars spread beyond the margins of the original wound, while hypertrophic scars, in which the immune cell infiltrate decreases over time, remain within the original wound margins and often regress over time. $^{7}$

Multiple studies on hypertrophic scar or keloid formation have led to a multitude of therapeutic strategies to prevent or improve keloid and hypertrophic scar formation and have been reviewed in a plethora of articles. However, only a few of them have been supported by well-designed prospective studies with adequate control groups. Today, most of the propagated therapeutic approaches are usually being utilized for both hypertrophic scarring and keloids. Nevertheless, clinical differentiation between hypertrophic and keloid scars is central before the initiation of any treatment, particularly before starting any surgical or ablative laser related manipulation, due to increased recurrence rates with keloids.

\section{Surgical aspects for the prevention and treatment of keloids and hypertrophic scars}

Surgical approaches for the prevention and treatment of hypertrophic scars and keloids should be based on five main principles.

1. General prophylactic approaches to minimize the risk of postoperative excessive scarring:

- Delayed epithelialization beyond 10-14 days is known to increase the incidence of hypertrophic scarring dramatically, ${ }^{10}$ thus achievement of rapid epithelialization is mandatory for avoiding excessive scar formation.

- Wounds subjected to tension due to motion, body location, or loss of tissue are at increased risk of scar hypertrophy and spreading, and patients should be informed of this important matter prior to any surgery. ${ }^{11}$

- Aesthetic wound closure is based on knowledge of healing mechanisms and skin anatomy, as well as an appreciation of suture material and closure technique. Choosing the proper materials and wound closure technique ensures optimal healing. Surgical wound closure directly opposes the tissue layers, which serves to minimize new tissue formation within the wound. Appropriate surgical wound closure eliminates dead space by approximating the subcutaneous tissues, minimizes scar formation by careful epidermal alignment, and avoids depressed scars by precise eversion of skin edges. If dead space is limited with opposed wound edges, then new tissue has limited room for growth. Correspondingly, traumatic handling of tissues combined with avoidance of tight closures and undue tension on wound margins by carefully undermining and loosening the surrounding tissue contribute to a better result. We do prefer subcutaneous sutures with, for example, PDS II (polydioxanone) monofilament synthetic absorbable sutures, which provide extended wound support (for up to 6 months) and may be combined with absorbable sutures or Steri-Strip ${ }^{\mathrm{TM}}$ (3M, St Paul, MN, USA) for optimal epidermal wound closure. The group of Ogawa and colleagues employs subcutaneous fascial tensile reduction sutures in their predisposed patient population, where the tension is placed on the layer of deep fascia and superficial fascia. The group prefers 2-0 PDS II or 3-0 PDS II sutures for subcutaneous/fascial sutures, and 4-0 or 5-0 PDS II for dermal sutures. ${ }^{12}$ 
Table I Basic recommendations for the treatment of keloids and hypertrophic scars based on the experience of the author

\begin{tabular}{|c|c|c|c|c|}
\hline Diagnosis & Start with & If no improvement & If improvement & If no improvement \\
\hline $\begin{array}{l}\text { I. Fresh surgical scar } \\
\text { (patients at risk) }\end{array}$ & $\begin{array}{l}\text { Silicone gel or onion extract } \\
\text { containing gel (starting } 2 \text { weeks } \\
\text { after wounding for } 3 \text { months) }\end{array}$ & $\begin{array}{l}\text { eg, persisting } \\
\text { erythema: PDL }\end{array}$ & & \\
\hline $\begin{array}{l}\text { 2. Immature, small } \\
\text { keloid/hypertrophic } \\
\text { scar }\end{array}$ & $\begin{array}{l}\text { TAC (10 mg/mL, women, } \\
20 \mathrm{mg} / \mathrm{mL}, \mathrm{men})\end{array}$ & $\begin{array}{l}\text { Cryotherapy } \\
\text { (10-15 seconds) directly } \\
\text { followed by TAC until } \\
\text { scar has flattened }\end{array}$ & $\begin{array}{l}\text { PDL to reduce } \\
\text { erythema }\end{array}$ & $\begin{array}{l}\text { 5-FU 3:I TAC (every other } \\
\text { week; eg, for acne keloids on } \\
\text { the shoulders) }\end{array}$ \\
\hline $\begin{array}{l}\text { 3. Large hypertrophic } \\
\text { scar }\end{array}$ & $\begin{array}{l}\text { If tension present: surgical relief } \\
\text { of tension by, eg, z-, w-plasty } \\
\text { (followed by topical agents as } \\
\text { indicated above/main text) } \\
\text { If no tension present: } \\
\text { cryotherapy (I0-I5 seconds) } \\
\text { directly followed by TAC until } \\
\text { scar has flattened }\end{array}$ & $\begin{array}{l}\text { 5-FU 3:I TAC } \\
\text { (every other week) }\end{array}$ & $\begin{array}{l}\text { PDL to reduce } \\
\text { erythema }\end{array}$ & Surgical excision, ablative laser \\
\hline 4. Large keloid & $\begin{array}{l}\text { Cryotherapy ( } 10-15 \text { seconds) } \\
\text { directly followed by TAC until } \\
\text { scar has flattened }\end{array}$ & $\begin{array}{l}\text { 5-FU 3:I TAC } \\
\text { (every other week) } \\
\text { Intralesional cryotherapy }\end{array}$ & $\begin{array}{l}\text { PDL to reduce } \\
\text { erythema }\end{array}$ & $\begin{array}{l}\text { Surgical excision (in combination } \\
\text { with, eg, radiotherapy, } \\
\text { intralesional TAC) }\end{array}$ \\
\hline
\end{tabular}

Abbreviations: 5-FU, 5-fluorouracil; PDL, pulsed dye laser; TAC, triamcinolone acetonide.

2. In the case of hypertrophic scarring, timing of surgical treatment is an important consideration in the treatment protocol of scar revision strategy. Hypertrophic scars may mature over at least a 1-year period and can show significant flattening and softening without any physical manipulation. ${ }^{13}$ Surgical excision might thus not be needed, even though post-excisional recurrence rates of the original hypertrophic scar are usually low. ${ }^{14,15}$ However, if scar (joint) contractures are present, surgical approaches that release contractures should be performed earlier. ${ }^{12}$

3. Increased tension on wound margins represents a central aspect in the development of hypertrophic scars. Thus, successful and persisting removal of excessive scar tissue may be achieved by employing Z- or W-plasty, grafts or local skin flaps to interrupt the vicious circle between scar tension and consecutive further thickening of the scar due to permanently stimulated ECM production. ${ }^{16}$

4. Hypertrophic scars and keloids that have developed on the basis of delayed wound healing (eg, after deep dermal burn or wound infection) are transformed by surgery (excision with suture or graft) into a wound with appropriate healing time, thus minimizing the risk of a new excessive scar formation. ${ }^{16}$

5. By surgical removal of excessive scar tissue, a situation corresponding to a fresh wound is achieved, in which renewed excessive scarring can be reduced by adjuvant conservative therapy from the very beginning. ${ }^{16}$ However, excision of keloids without any adjuvant therapy (eg, post-excisional corticosteroid injections, 5-fluorouracil (5-FU), intraoperative cryotherapy, pressure, or radiations) should be strictly avoided due to great recurrence rates (45\%-100\%). Excisions of the keloid may result in a longer scar than the original one, and recurrence in this new area of trauma may lead to an even larger keloid. ${ }^{17,18}$ Interestingly, surgical repair (core excision with low-tension wound closure, or shave excision) of earlobe keloids with postsurgery corticosteroid injections, postoperative pressure (pressure earrings), application of imiquimod 5\% cream, or cryotherapy on the incision site has been shown to provide overall good cosmetic results. ${ }^{19}$

\section{Current strategies for the treatment of hypertrophic scars and keloids Intralesional corticosteroid injections and cryotherapy}

Intralesional steroid injections have been used for the therapy of excessive scars since the mid-1960s. ${ }^{20}$ To date, the use of intralesional triamcinolone acetonide represents the therapy of choice for small and younger keloids as well as hypertrophic scars ${ }^{10,16}$ and effectively provides symptomatic relief by reducing pruritus. Effects of corticosteroids result primarily from their suppressive effects on the inflammatory process in the wound, ${ }^{13}$ and secondarily from reduced collagen and glycosaminoglycan synthesis, inhibition of fibroblast growth, ${ }^{21}$ as well as enhanced collagen and fibroblast degeneration. ${ }^{22}$ Three to four injections of triamcinolone acetonide (TAC) $(10-40 \mathrm{mg} / \mathrm{mL})$ every 3-4 weeks are generally sufficient, although occasionally injections continue for 6 months 
or more. ${ }^{20}$ Response rates vary from $50 \%$ to $100 \%$, and recurrence rates from $9 \%$ to $50 \% .{ }^{18}$ Adverse events include dermal atrophy, telangiectasia, and pain at the injection site. The latter can be averted by topical anesthesia and/or regional injections of local anesthetic around the scars to be injected. ${ }^{2}$ For older hypertrophic scars and larger keloids, the combination with cryotherapy appears more effective ${ }^{23,24}$ and currently represents the most widely used modality in daily routine. Indeed, combination of cryotherapy with intralesional TAC injections seems to yield marked improvement of hypertrophic scars and keloids. ${ }^{25-27}$ Cryotherapy is believed to induce vascular damage that may lead to anoxia and ultimately tissue necrosis. ${ }^{28}$ A delay of approximately 3-4 weeks between sessions (approximately three to six sessions are needed) is usually required for postoperative healing, and commonly occurring side effects include permanent hypo- and hyperpigmentation, blistering, and postoperative pain. ${ }^{29-31}$

We usually perform cryotherapy directly before the injection of TAC, since success rates appear to be increased based on the larger amount of TAC that can be injected into the scar due to edema formation caused by cryotherapy.

\section{Pressure therapy}

Pressure therapy has gained popularity for the management of hypertrophic scars and keloids since the 1970s. To date, pressure garments are frequently being used for the prevention of excessive scar formation post-burn. However, their underlying mechanism of action remains poorly understood. Decreased collagen synthesis by limiting capillary perfusion and thus decreased oxygen supply to the scar tissue ${ }^{32-34}$ as well as increased apoptosis rates of fibroblasts ${ }^{35}$ are being discussed. Pressure therapy is usually performed with pressure suits or bandages, sometimes with transparent plastic masks or pressure buttons in special locations. Recommendations for the amount of pressure and the duration of the therapy are merely based on empirical observations and support continuous pressure of $15-40 \mathrm{mmHg}$ for at least 23 hours per day for more than 6 months while the scar is still active. ${ }^{33,36} \mathrm{In}$ a recent study, the use of $20-25 \mathrm{mmHg}$ was significantly superior to treatment of hypertrophic scars with $10-15 \mathrm{mmHg} .{ }^{37}$ Nevertheless, no definite positive effect of compression garments was found in a recently published meta-analysis. ${ }^{38}$ Pressure therapy may be also limited by the ability to adequately fit the garment to the wounded area and by reduced compliance (particularly in patients of reduced psychological strain) due to side effects such as maceration, eczema, and odor emanating from the garment. However, postoperative pressure (eg, pressure earrings) appears to markedly reduce recurrence rates after surgical repair of earlobe keloids ${ }^{39,40}$ and may thus be recommended as an easy-to-use post-surgical procedure. Also, pressure garments may represent a promising alternative to intralesional TAC or cryotherapy for the treatment of hypertrophic scars and keloids in younger children. First, pressure therapy eliminates the significant side effects (lipoatrophy, blistering, and pain) frequently observed with intralesional corticosteroids or cryotherapy in this specific patient population. And second, based on our experience, pressure therapy usually demonstrates superior results in children compared with adults.

\section{Radiotherapy}

Superficial X-rays, electron beam and low- or high-dose-rate brachytherapy have been employed primarily as an adjunct to surgical removal of keloids, with overall good results in terms of reduced recurrence, ${ }^{41-44}$ with the exception of one report. ${ }^{45}$ Radiation mediates its effects through inhibition of neovascular buds and proliferating fibroblasts, resulting in decreased collagen production. ${ }^{13}$ Electron beam irradiation should be started early (24-48 hours) after keloid excision. A total dose of usually 12 Gy divided into six to ten fractions applied daily or every second day is currently recommended by dermatologists. ${ }^{16}$ Side effects include hypo- and hyperpigmentation, erythema, telangiectasia, and atrophy. ${ }^{46}$ Since radiation represents some risk in terms of carcinogenesis, particularly in areas such as the breast or thyroid, its use should be handled with caution. ${ }^{14,29}$

\section{Laser therapy}

Various lasers have been evaluated in the past decades for the improvement of hypertrophic scars and keloids. ${ }^{47}$ However, current data is difficult to compare due to the different laser settings utilized. The most encouraging results have been demonstrated with the 585-nm pulsed dye laser (PDL), which was first described as promising for the treatment of younger hypertrophic scars and keloids in a milestone study by Alster et al published in the Lancet in $1995 .{ }^{53}$ It is thought that the PDL improves keloids or hypertrophic scars by inducing capillary destruction, which generates hypoxemia and in turn alters local collagen production. ${ }^{48-50}$ Also, increased production of MMPs (eg, collagenase) has been described upon PDL treatment. ${ }^{51}$ Non-overlapping laser pulses at fluences ranging from 6.0 to $7.5 \mathrm{~J} / \mathrm{cm}^{2}$ (7-mm spot) or from 4.5 to $5.5 \mathrm{~J} / \mathrm{cm}^{2}$ (10-mm spot) are currently recommended for the treatment of hypertrophic scars and keloids. ${ }^{52}$ According to Alster and colleagues, two to six treatment sessions are necessary to successfully improve scar color, height, pliability, and texture. ${ }^{53}$ 
However, these findings could not be reproduced in several subsequent studies; ${ }^{54}$ in particular, the results in some casecontrol studies did not differ from the untreated control groups after longer follow-up observation periods. ${ }^{55,56}$ Thus, due to the lack of untreated controls, too small case numbers, too short follow-up periods, lack of differentiation between hypertrophic scars and keloids, or lack of information on the age and activity of the scars, the majority of published studies do not possess sufficient evidence. ${ }^{57}$ Side effects are generally mild and include predominantly purpura, usually persisting for 7-14 days. Depending on the energy density employed, vesicles and crusts may occur. Longer persisting hyperpigmentation occurs particularly in darker skin types and is less frequent with use of the wavelength $595 \mathrm{~nm}$ than with $585 \mathrm{~nm} .{ }^{16}$ Occasionally, reactivation of younger keloids is observed, as experienced in our daily praxis and by others. ${ }^{58}$ We thus usually recommend initiating treatment of keloids using the combination of cryotherapy and TAC and employ the PDL to reduce erythema (Figure 1).

Recently, the 1064-nm Neodym: YAG laser has been suggested as a promising means for the improvement of keloids and hypertrophic scars. ${ }^{51}$ Underlying mechanisms of action may be similar to those of PDL therapy, however, the Nd:YAG reaches greater depths than a PDL. Its ability to treat thick keloids, however, may be limited since its efficacy decreases with the thickness of the scar. ${ }^{51}$ Cho and colleagues found improvements of pigmentation, vascularity, pliability, and scar height in a small Korean patient population with keloids and hypertrophic scars after five to ten treatments (at 1-2-week intervals) using low fluences. Side-effects were mild and included a prickling sensation during treatment and post-treatment erythema. ${ }^{59}$ Nevertheless, more studies are necessary to elucidate the ultimate effect of an Nd:YAG laser for the treatment of hypertrophic scars and keloids. Thus, based on the recently published German guidelines for the therapy of excessive scarring, it is primarily PDL that can be recommended for reduction of erythema, eg, in fresh, highly vascularized, red scars, and can also be considered for improvement of severe pruritus. ${ }^{16}$ According to these guidelines, a treatment with conventional $\mathrm{CO}_{2}$ or Erbium: YAG lasers may be recommended for the ablation of inactive hypertrophic scars; their use for removal of keloids as monotherapy, however, should be avoided due to recurrence rates similar to that after excision of keloids. ${ }^{16}$ The combination with post$\mathrm{CO}_{2}$-laser steroid injections 3-4 weeks apart for a total of 6 months, however, seems to yield convincing results. ${ }^{60}$ Due to a lack of controlled studies, no statement can yet be made on the use of fractional $\mathrm{CO}_{2}$ lasers in hypertrophic scars. ${ }^{16}$

\section{Silicone based products}

Silicone gel sheeting represents a well-known management for scars since its introduction in the early 1980s, and its therapeutic effect on unpleasant scars has been well studied. ${ }^{61-65}$ Current opinion suggests that normalization of transepidermal water loss is likely the underlying mechanism of silicone gel products rather than an inherent anti-scarring property of silicone. ${ }^{13,66}$ Silicone sheets are usually being employed 12-24 hours per day over a period of $12-24$ weeks ${ }^{16}$ beginning 2 weeks after wounding. Currently published studies are concluding mostly positively in favor of the evaluated silicone-based therapy. A recent Cochrane review, however, determining the effectiveness of silicone gel sheeting in the treatment and
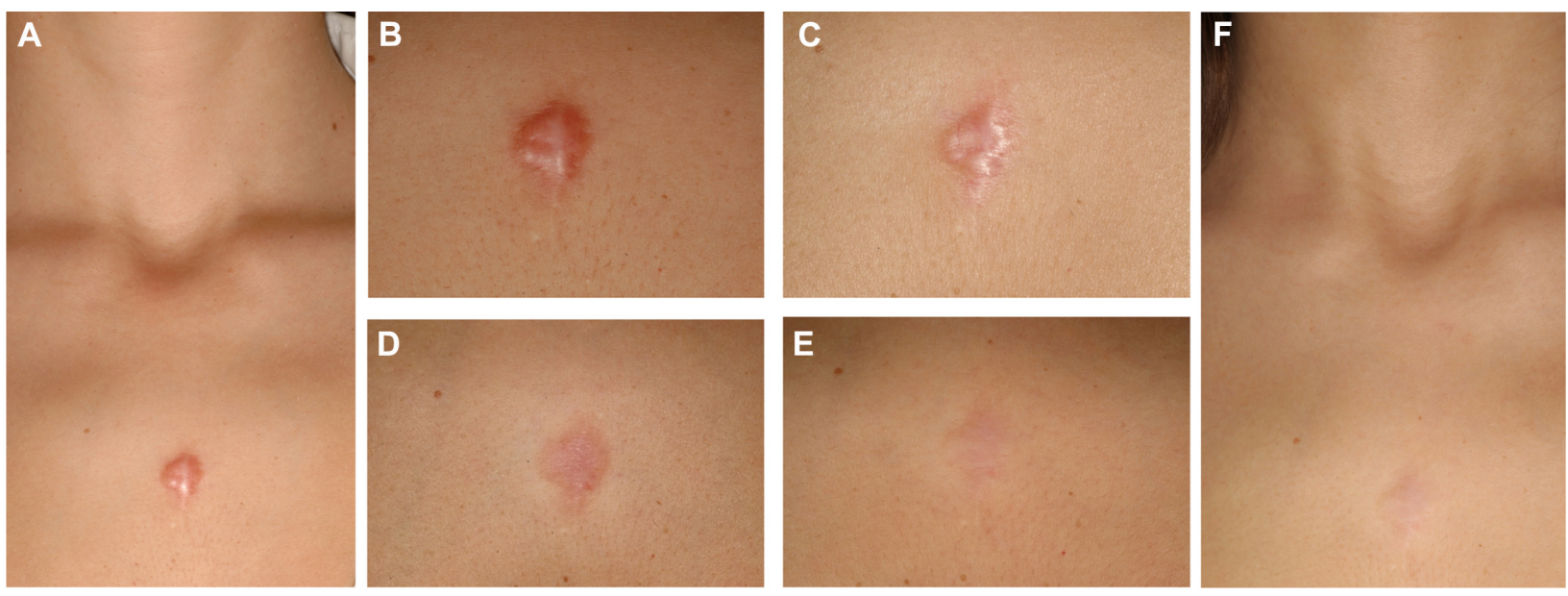

Figure I Baseline photograph at presentation in our scar clinic before initiation of combination therapy with cryotherapy directly followed by intralesional TAC (I0 mg/mL) $(\mathbf{A}$ and $\mathbf{B})$. Result after three cycles of combined cryo/intralesional TAC therapy before initiation of PDL (C). Result after four PDL applications (D). No signs of recurrence or reactivation at follow-up 6 months after the last laser treatment ( $E$ and $\mathbf{F}$ ).

Abbreviations: PDL, pulsed dye laser; TAC, triamcinolone acetonide. 
prevention of keloid and hypertrophic scarring concluded that most studies are of poor quality and thus the efficacy of silicone gel sheets remains unclear. ${ }^{67}$ Nevertheless, the current version of the international guidelines on scar management published in 2002 promotes silicone gel sheeting as first-line therapy for linear hypertrophic, widespread burn hypertrophic scars and minor keloids. ${ }^{10}$ In the past years, more and more studies have convincingly supported the use of silicone gels for prophylaxis of unpleasant scarring, particularly in areas of consistent movement where sheeting will not conform. ${ }^{68-72}$ The ultimate benefit of silicone gels on mature hypertrophic scars and keloids, however, remains contradictory.

\section{Emerging options for the management of excessive scarring}

\section{5-FU}

Since 1989, 5-FU has been successfully used for the therapy of keloids and hypertrophic scars, as demonstrated by Fitzpatrick and colleagues. ${ }^{73}$ 5-FU inhibits the proliferation of fibroblasts as a pyrimidine analog. The response rate in keloids is an estimated $50 \%{ }^{74}$ So far, most studies use the high-dose version of 5-FU therapy $(40-50 \mathrm{mg} / \mathrm{mL})$ aiming to destroy the keloid. In 2006, Liu et $\mathrm{al}^{75}$ and $\mathrm{Wu}$ et $\mathrm{al}^{76}$ promoted a "low-dose" therapy using $1.4-3.5 \mathrm{mg} / \mathrm{mL} 5-\mathrm{FU}$ in 35 patients with 51 keloids. In 2008 and 2009, the same group could demonstrate the effectiveness of this therapy in 83 patients with a total of 166 keloids on the ear. ${ }^{77}$ Other studies are supporting the combination of 5-FU and TAC. In a prospective study with a total of 69 patients, the combination of TAC ( $40 \mathrm{mg} / \mathrm{mL})$ and 5-FU (50 mg/mL) (1:9) once weekly for 2 months, injected strictly intralesionally, was shown to be superior to exclusive weekly injection of TAC $40 \mathrm{mg} / \mathrm{mL} .{ }^{78} \mathrm{In}$ another double-blind, prospective study on 40 patients with keloids and hypertrophic scars, better results with respect to reduction in size and redness were seen with the combination TAC $(40 \mathrm{mg} / \mathrm{mL}) / 5-\mathrm{FU}(50 \mathrm{mg} / \mathrm{mL})$ (1:9) compared with the injection of TAC $40 \mathrm{mg} / \mathrm{mL}$ alone. ${ }^{79}$ Strictly intralesional injection of a combination of 5-FU $(50 \mathrm{mg} / \mathrm{mL})$ and TAC $(40 \mathrm{mg} / \mathrm{mL})(1: 3)$ for the treatment keloids was examined in a retrospective study with either 5-FU/TAC/excision or TAC/ excision in a total of 102 patients, with the combination of 5-FU/TAC/excision proving to be superior to the combination TAC/excision. ${ }^{80} \mathrm{We}$ are following a similar dose regime for keloids resistant to cryotherapy and TAC. Treated scars do demonstrate significant flattening after two to four sessions, and pruritus resolves usually very quickly (Figure 2). However, for further aesthetic improvement, a PDL may be employed later on to decrease erythema and potential
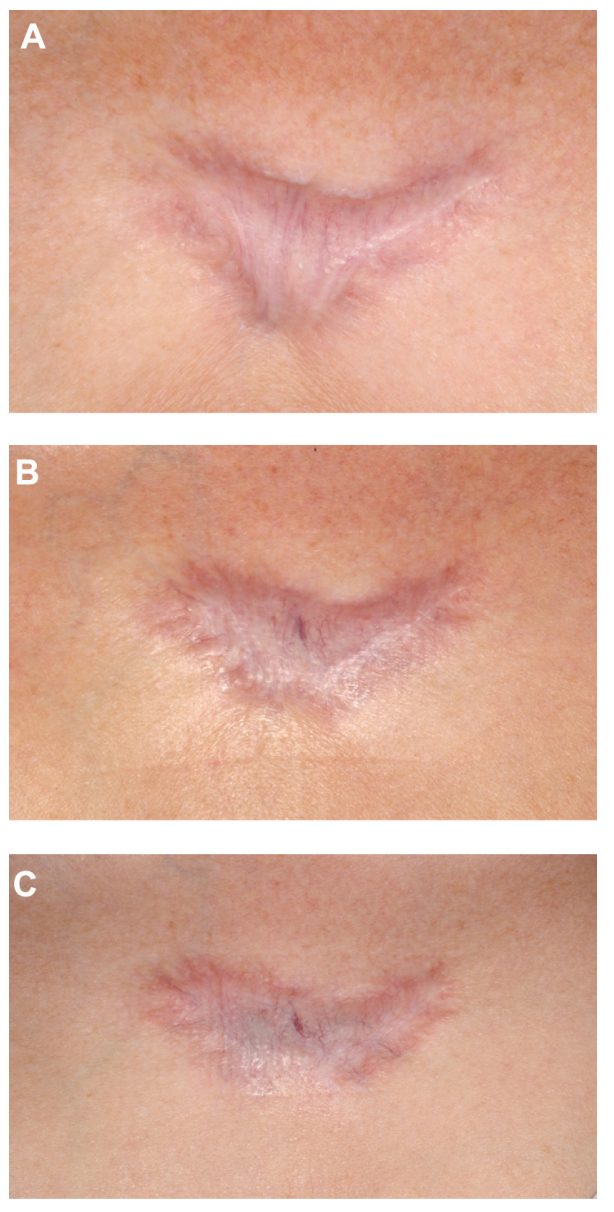

Figure 2 Patient with keloid in the presternal area resistant to cryotherapy and TAC, silicone gel sheeting, surgery and postoperative radiotherapy (recurrence) suffering from severe pruritus at baseline $(\mathbf{A})$. Significant reduction of pruritus and flattening after I week of injection with 5-FU $(50 \mathrm{mg} / \mathrm{mL})$ and TAC $(40 \mathrm{mg} / \mathrm{mL})$, 3:I (B). Result at 6 months after the last injection (two injections total), with no signs of recurrence, no pruritus (C).

Abbreviations: 5-FU, 5-fluorouracil; TAC, triamcinolone acetonide.

telangiectasia. Based on the currently available study data, the use of 5-FU for the treatment of keloids represents a safe approach. Side effects include pain at the injection site, hyperpigmentation, skin irritation, and ulceration; the latter is mainly seen in dark-skinned individuals and resolves within weeks. Listed contraindications are, among others, anemia, leukopenia, thrombocytopenia, pregnancy, bone marrow depression, and infection. Systemic side effects have not been observed to date. Based on the updated German guidelines for the therapy of pathological scarring, treatment of therapyrefractory keloids with 5-FU can be considered. ${ }^{16}$

\section{Onion extract (extractum cepae)}

Extractum cepae acts in an anti-inflammatory manner and is bactericidal. It is currently believed that the flavonoids (quercetin and kaempferol) in onion extract play the main role in reducing scar formation through inhibition of 
fibroblast proliferation and collagen production. A study by Phan and others suggested that these inhibitory effects may be mediated through inhibition of TGF- $\beta 1$ and $-\beta 2$ and SMAD proteins by quercetin. ${ }^{81,82}$ Today, an increasing body of literature is available testing the ultimate benefit of onion extract containing scar creams. ${ }^{83-87}$ Nevertheless, former clinical results are in part contradicting regarding its efficacy. However, based on recent studies, onion extract containing scar creams do significantly improve scar height and associated symptoms compared with placebo ${ }^{84}$ and appear to be effective for the prevention of unpleasant scars in patients having laser removal of tattoos ${ }^{88}$ as well as in combination with intralesional triamcinolone acetonide. ${ }^{89}$ Based on the recently published German guidelines on scarring, onion extract-containing scar creams can be considered as additional therapy for active hypertrophic scars and for post-surgical prophylaxis of excessive scarring. ${ }^{16}$

\section{Intralesional cryotherapy}

Recently, a novel intralesional cryosurgery cryoneedle (CryoShape, Etgar Group Ltd, Kfar Saba, Israel) has been introduced. ${ }^{90-92}$ The probe which is inserted into the hypertrophic scar or keloid, is connected to a canister of liquid nitrogen, which causes the cryoneedle to freeze thereby freezing the scar tissue from the inside out (Figure 3). An average of $51 \%$ of scar volume reduction was achieved following a single cryogenic treatment. Scar volume reduction of $70 \%$ for ear keloids and $60 \%$ for keloids on the upper back, shoulder, and chest was achieved following a single cryo-session, as demonstrated in a recent study ${ }^{84}$ Significant

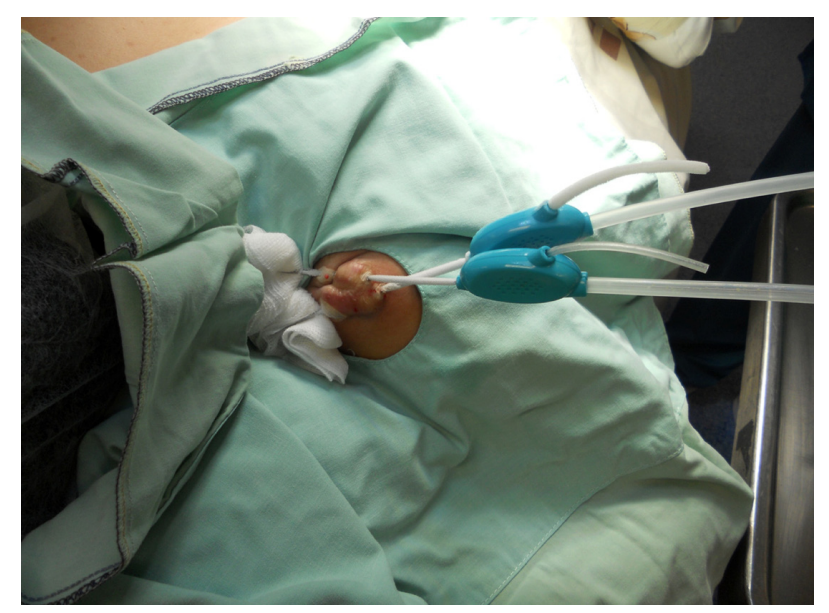

Figure 3 With intralesional cryotherapy, a specially designed cryoneedle is inserted (under translesional local anesthesia) into the long axis and mid height of the respective keloid.

Notes: The cryoneedle is then connected by an adaptor to a cryogun filled with liquid nitrogen, which is introduced into the cryoprobe, thereby freezing the keloid. After complete freezing of the lesion, the cryoprobe defrosts and is withdrawn. alleviation of clinical symptoms was achieved. No worsening or infection of the treated scars was noticed, and only minimal hypopigmentation was evident. The non-response rate of this technique was less than $3 \%$. This technology demonstrates increased efficacy compared with that obtained with contact/spray probes and may thus represent a promising alternative scar reduction strategy. ${ }^{93}$ Although this technology is relatively costly, it appears comparatively cost-effective, since frequently a single cryo-session is sufficient, in order to significantly improve the hypertrophic scar or keloid (Figure 4).

\section{Imiquimod}

Imiquimod 5\% cream, a topical immune response modifier, has been approved for the treatment of actinic keratoses, superficial basal cell carcinoma, and genital warts. ${ }^{78}$ Imiquimod stimulates interferon, a pro-inflammatory cytokine, which increases collagen breakdown. Additionally, imiquimod alters the expression of apoptosis-associated genes. ${ }^{94}$ It has been used in several trials, observational studies and case reports to reduce keloid recurrence after excision
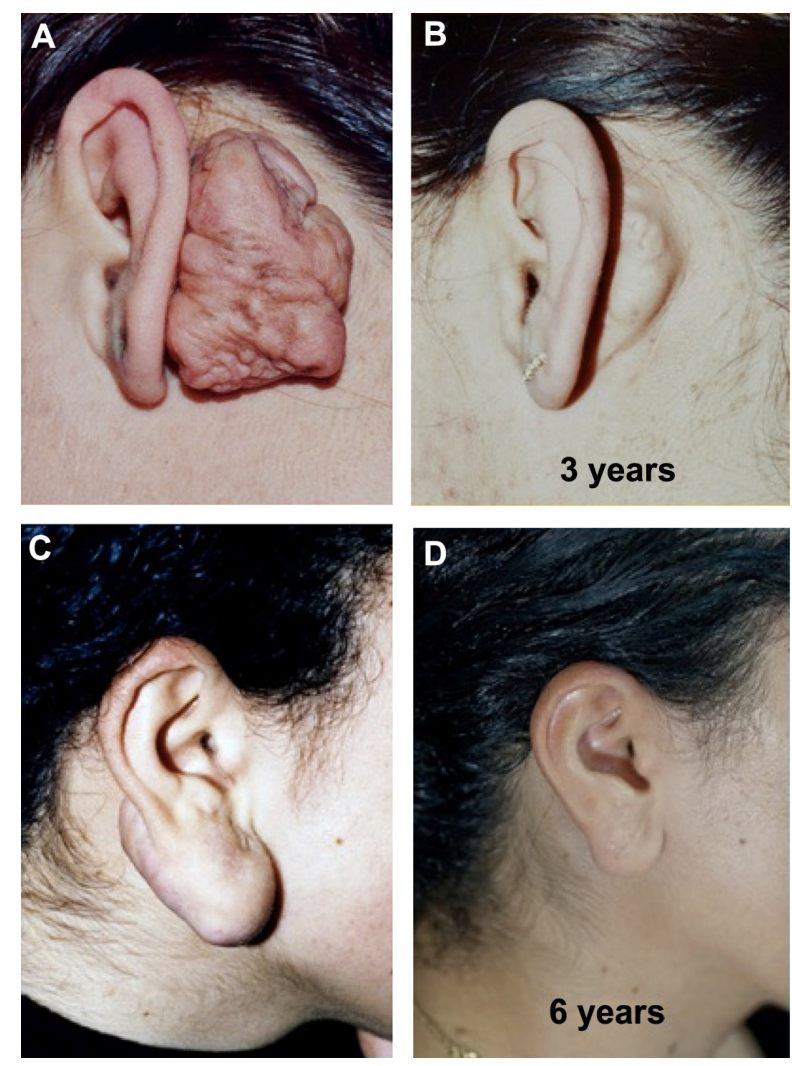

Figure 4 Result at baseline (A and $\mathbf{C}$ ) and after 3 and 6 years, respectively (B and $\mathbf{D})$ post-intralesional cryotherapy.

Adapted with permission from Har-Shai Y. Intralesional cryosurgery for enhancing the involution of hypertrophic scars and keloids. A new effective technology based on experimental and clinical data. Journal of Wound Technology. 2012;15:8-9.118 
and was reported to have positive effects on the recurrence rate of keloids if applied post-surgery utilizing different treatment regimes (starting on the night of surgery with daily treatments or 2 weeks after the operation every alternate night for 8 weeks). ${ }^{95-98}$ However, in a recent prospective, doubleblind, placebo-controlled pilot study including 20 patients undergoing keloid excision and subsequent treatment with imiquimod $5 \%$ cream or placebo, no significant differences in 6-month keloid recurrence rates were detected between groups due to lack of statistical power. ${ }^{99}$ Another study revealed contradicting data (keloid recurrence in 8 out of 10 patients treated with imiquimod 5\%). ${ }^{100}$ Thus additional studies may be necessary to further characterize the ultimate success rates and the side effect profile (eg, persisting inflammation, erosion, depigmentation) of this rather expensive approach for the reduction of recurrence rates after surgery of keloids.

\section{Bleomycin}

Bleomycin sulfate is thought to inhibit collagen synthesis via decreased stimulation by TGF- $\beta 1 .{ }^{101}$ Some studies demonstrate significant improvement in hypertrophic scar and keloid height and pliability as well as reduction in erythema, pruritus, and pain after three to five injections (via multiple needle puncture or jet injections) of bleomycin $(1.5 \mathrm{IU} / \mathrm{mL}) \cdot{ }^{101-103}$ Sporadically, development of depigmentation and dermal atrophy has been noted. Due to its toxicity, clinicians are encouraged to be aware of associated potential problems. However, systemic toxic effects of intralesionally administered bleomycin appear to be rare ${ }^{14}$ Bleomycin may thus represent a promising agent for the therapy of keloids and hypertrophic scars; however, further investigation and efficacy trials are necessary to include this agent in future treatment protocols.

\section{Interferon (IFN)}

Based on the finding that IFN markedly decreases synthesis of collagen I and III, IFN has been suggested as an effective means for the improvement of excessive scars. ${ }^{14,104}$ Particularly, IFN- $\alpha 2 b$ has been proposed to have antiproliferative properties and may improve the pathologic features of dermal fibrosis directly or by antagonizing the effects of TGF- $\beta$ and histamine. ${ }^{105}$ Intralesional injection of IFN- $\alpha 2 b$ (1.5 million IU, given twice daily over 4 days) resulted in $50 \%$ reduction of keloid size after only 9 days and was thus more effective compared with intralesional corticosteroids. ${ }^{105}$ Also, hypertrophic scars injected three times weekly with IFN- $\alpha 2 b$ demonstrated significant improvement and sustained reduced serum TGF- $\beta$ levels. ${ }^{106}$ However, side effects are common with IFN and include flu-like symptoms and pain on the injection site. ${ }^{14}$ Even though IFN represents an expensive form of therapy, it may represent a promising therapeutic approach particularly for the therapy of keloids resistant to any other treatment.

\section{Botulinum toxin A (BTA)}

BTA immobilizes local muscles, reduces skin tension caused by muscle pull, and thus, decreases microtrauma and subsequent inflammation. ${ }^{107}$ Reduction of the tensile force during the course of cicatrisation and effective regulation of the balance between fibroblast proliferation and cellular apoptosis ${ }^{108}$ may represent a novel therapeutic option for the aesthetic improvement of post-surgical scars. Indeed, Gassner and colleagues could demonstrate that botulinum toxin injections into the musculature adjacent to the wound (15 U of BTA (Botox, Allergan, Irvine, CA, USA) per $2 \mathrm{~cm}$ intraoperative length) within 24 hours after wound closure resulted in enhanced wound healing and less noticeable scars compared with placebo. ${ }^{109}$ By injecting BTA 4-7 days prior to surgery, we have seen similar results using a slightly reduced dose regime, depending on the respective anatomic location (risk of severe asymmetry if injecting only one side of the musculus frontalis, brow ptosis).

Recently, intralesional injection with BTA has been proposed for the treatment of established keloids in a prospective, uncontrolled study. ${ }^{110}$ BTA was injected into the lesions at 3-month intervals for a maximum of 9 months at a concentration of 35 units $/ \mathrm{mL}$. Total doses ranged from 70 to 140 units per session. At 1-year follow up, three of the included 12 patients demonstrated excellent, five good, and four fair results. In none of the patients did this therapy fail. When analyzing clinical symptoms, scar regression was noted from the periphery in all of the patients followed by flattening of the lesions. Within the follow-up period of 1 year, no signs of recurrence were noted in any of the patients. As an underlying mechanism, reduction of TGF$\beta 1$ expression and decreased fibroblasts, proliferation was suggested. ${ }^{111}$ In a recently published study by our group, objective evaluation of BTA-treated keloids using optical profilometry did not reveal any changes after BTA therapy compared with baseline. ${ }^{12}$ Also, no in-vitro effects of BTA on TGF- $\beta$ subtypes or fibroblast proliferation could be found. Thus, while reduction of the tensile force by prophylactic BTA injections into the musculature adjacent to the respective wound might represent a comprehensible mechanism of action for aesthetic improvement of post-surgical scars, the suggested clinical efficiency of intralesional BTA for the 
treatment of existent keloids remains uncertain. Certainly, more in-depth studies on the effects of BTA on pathologic scars and/or mature keloids are needed before a comparatively expensive therapy for this particular indication can be postulated.

\section{Photodynamic therapy (PDT)}

Topical PDT has been used extensively in treating superficial basal cell carcinoma, actinic keratosis, and Bowen's disease. Very recently, PDT has been suggested as a novel therapeutic approach for the treatment of keloids. The potential underlying mechanism is currently unknown. However, the photodynamic reaction generates reactive oxygen species, which in turn leads to cell apoptosis, membrane and mitochondrial damage, and activates various signaling molecules such as tumor necrosis factor- $\alpha$. PDT has been demonstrated to reduce type I collagen synthesis and fibroblast proliferation in vitro, which may be responsible for the improvement seen clinically. ${ }^{113,114} \mathrm{Ud}$-Din et al recently demonstrated in 20 patients that three treatments of PDT $\left(37 \mathrm{~J} / \mathrm{cm}^{2}\right)$ at weekly intervals were effective in reducing pruritus and pain, and in increasing pliability of symptomatic keloids. Also, when applied postoperatively after excision of keloids, no recurrence rates were seen at 9-month follow-up, with the exception of one patient. ${ }^{115}$ Based on this small amount of data available, PDT represents a promising, noninvasive treatment which produces a good cosmetic outcome with minimal side effects. However, more studies are needed to further evaluate the optimal PDT treatment regime for this indication.

\section{Recombinant TGF- $\beta 3$, Justiva (avotermin)}

In 2009, Ferguson and colleagues summarized the results of three double-blind, placebo-controlled trials in a milestone study published in the Lancet: ${ }^{116}$ Intradermal avotermin (recombinant, active, human TGF- $\beta 3$, Justiva) was administered in healthy subjects to both margins of $1 \mathrm{~cm}$, full-thickness skin incisions, before wounding and 24 hours later and was judged to be effective by lay observers and clinicians. Even though the investigators acknowledged their commercial interests in TGF- $\beta 3$, adherence to established standards in this translational investigation and the rigorous nature of the statistical analysis in a well powered series of studies provided strong evidence for the benefits of Justiva in this setting. However, in spring 2011, Justiva failed to hit its primary and secondary endpoints in a pivotal Phase III trial. In light of these findings, the company regrettably concluded that the efficacy of Justiva may be insufficient to demonstrate significant benefit when tested in a broad population of scar revision patients. ${ }^{117}$ To date, the clinical future of recombinant TGF- $\beta 3$ remains uncertain.

\section{Conclusion}

Scarring following surgery or trauma is difficult to predict, and both physicians and their patients are highly concerned with minimizing scar appearance, and value even small improvements in scarring as clinically meaningful. Existing prophylactic and therapeutic strategies include pressure therapy, silicone gel (sheeting), intralesional triamcinolone acetonide, cryotherapy, radiation, lasers, surgical excision, and advocates their combination (Table 1). Many of them have been proven through extensive use, but few have been supported by well-designed prospective studies with adequate control groups. Emerging techniques such as intralesional 5-FU, IFN, and intralesional cryotherapy have successfully been tested in well-designed trials and already have or may extend the current spectrum of excessive scar treatment in the future. Innovative options such as imiquimod cream, PDT, and BTA may be of certain importance; however, the little data available is too contradicting for definite recommendations.

\section{Disclosure}

Dr Gerd Gauglitz serves as advisor and speaker for Merz Pharmaceuticals, Sinclair Pharma, and MEDA Pharma.

\section{References}

1. Gauglitz GG, Korting HC, Pavicic T, Ruzicka T, Jeschke MG. Hypertrophic scarring and keloids: pathomechanisms and current and emerging treatment strategies. Mol Med. 2011;17(1-2):113-125.

2. Tredget EE, Nedelec B, Scott PG, Ghahary A. Hypertrophic scars, keloids, and contractures. The cellular and molecular basis for therapy. Surg Clin North Am. 1997;77(3):701-730.

3. Niessen FB, Spauwen PH, Schalkwijk J, Kon M. On the nature of hypertrophic scars and keloids: a review. Plast Reconstr Surg. 1999; 104(5):1435-1458.

4. Slemp AE, Kirschner RE. Keloids and scars: a review of keloids and scars, their pathogenesis, risk factors, and management. Curr Opin Pediatr. 2006;18(4):396-402.

5. Gauglitz GG, Pavicic T. [Emerging strategies for the prevention and therapy of excessive scars.] MMW Fortschr Med. 2012;154(15):55-58. German.

6. Bond JS, Duncan JA, Mason T, et al. Scar redness in humans: how long does it persist after incisional and excisional wounding? Plast Reconstr Surg. 2008;121(2):487-496.

7. Brown JJ, Bayat A. Genetic susceptibility to raised dermal scarring. Br J Dermatol. 2009;161(1):8-18.

8. Wynn TA. Fibrotic disease and the $\mathrm{T}(\mathrm{H}) 1 / \mathrm{T}(\mathrm{H}) 2$ paradigm. Nat Rev Immunol. 2004;4(8):583-594.

9. Doucet C, Brouty-Boye D, Pottin-Clemenceau C, Canonica GW, Jasmin C, Azzarone B. Interleukin (IL) 4 and IL-13 act on human lung fibroblasts. Implication in asthma. J Clin Invest. 1998;101(10):2129-2139.

10. Mustoe TA, Cooter RD, Gold MH, et al. International clinical recommendations on scar management. Plast Reconstr Surg. 2002;110(2): $560-571$.

11. Mutalik S. Treatment of keloids and hypertrophic scars. Indian $J$ Dermatol Venereol Leprol. 2005;71(1):3-8. 
12. Ogawa R, Akaishi S, Huang C, et al. Clinical applications of basic research that shows reducing skin tension could prevent and treat abnormal scarring: the importance of fascial/subcutaneous tensile reduction sutures and flap surgery for keloid and hypertrophic scar reconstruction. J Nippon Med Sch. 2011;78(2):68-76.

13. Reish RG, Eriksson E. Scar treatments: preclinical and clinical studies. J Am Coll Surg. 2008;206(4):719-730.

14. Leventhal D, Furr M, Reiter D. Treatment of keloids and hypertrophic scars: a meta-analysis and review of the literature. Arch Facial Plast Surg. 2006;8(6):362-368.

15. Muir IF. On the nature of keloid and hypertrophic scars. Br J Plast Surg. 1990;43(1):61-69.

16. Nast A, Eming S, Fluhr J, et al. German S2k guidelines for the therapy of pathological scars (hypertrophic scars and keloids). J Dtsch Dermatol Ges. 2012;10(10):747-762.

17. Poochareon VN, Berman B. New therapies for the management of keloids. J Craniofac Surg. 2003;14(5):654-657.

18. Robles DT, Berg D. Abnormal wound healing: keloids. Clin Dermatol. 2007;25(1):26-32.

19. Zuber TJ, DeWitt DE. Earlobe keloids. Am Fam Physician. 1994; 49(8):1835-1841.

20. Jalali M, Bayat A. Current use of steroids in management of abnormal raised skin scars. Surgeon. 2007;5(3):175-180.

21. Cruz NI, Korchin L. Inhibition of human keloid fibroblast growth by isotretinoin and triamcinolone acetonide in vitro. Ann Plast Surg. 1994;33(4):401-405.

22. Boyadjiev C, Popchristova E, Mazgalova J. Histomorphologic changes in keloids treated with Kenacort. J Trauma. 1995;38(2): 299-302.

23. Murray JC. Keloids and hypertrophic scars. Clin Dermatol. 1994;12(1): 27-37.

24. Lawrence WT. In search of the optimal treatment of keloids: report of a series and a review of the literature. Ann Plast Surg. 1991;27(2): 164-178.

25. Boutli-Kasapidou F, Tsakiri A, Anagnostou E, Mourellou O. Hypertrophic and keloidal scars: an approach to polytherapy. Int $J$ Dermatol. 2005;44(4):324-327.

26. Jaros E, Priborsky J, Klein L. [Treatment of keloids and hypertrophic scars with cryotherapy.] Acta Medica (Hradec Kralove) Suppl. 1999; 42(2):61-63. Czech.

27. Yosipovitch G, Widijanti Sugeng M, Goon A, Chan YH, Goh CL. A comparison of the combined effect of cryotherapy and corticosteroid injections versus corticosteroids and cryotherapy alone on keloids: a controlled study. J Dermatolog Treat. 2001;12(2):87-90.

28. Sharpe D. Of apples and oranges, file drawers and garbage: why validity issues in meta-analysis will not go away. Clin Psychol Rev. 1997;17(8): 881-901.

29. Atiyeh BS. Nonsurgical management of hypertrophic scars: evidencebased therapies, standard practices, and emerging methods. Aesthetic Plast Surg. 2007;31(5):468-494.

30. Zouboulis CC, Blume U, Buttner P, Orfanos CE. Outcomes of cryosurgery in keloids and hypertrophic scars. A prospective consecutive trial of case series. Arch Dermatol. 1993;129(9):1146-1151.

31. Barara M, Mendiratta V, Chander R. Cryotherapy in treatment of keloids: evaluation of factors affecting treatment outcome. J Cutan Aesthet Surg. 2012;5(3):185-189.

32. Baur PS, Larson DL, Stacey TR, Barratt GF, Dobrkovsky M. Ultrastructural analysis of pressure-treated human hypertrophic scars. J Trauma. 1976;16(12):958-967.

33. Macintyre L, Baird M. Pressure garments for use in the treatment of hypertrophic scars - a review of the problems associated with their use. Burns. 2006;32(1):10-15.

34. Kelly AP. Medical and surgical therapies for keloids. Dermatol Ther. 2004;17(2):212-218.

35. Reno F, Sabbatini M, Lombardi F, et al. In vitro mechanical compression induces apoptosis and regulates cytokines release in hypertrophic scars. Wound Repair Regen. 2003;11(5):331-336.
36. Van den Kerckhove E, Stappaerts K, Fieuws S, et al. The assessment of erythema and thickness on burn related scars during pressure garment therapy as a preventive measure for hypertrophic scarring. Burns. 2005;31(6):696-702.

37. Candy LH, Cecilia LT, Ping ZY. Effect of different pressure magnitudes on hypertrophic scar in a Chinese population. Burns. 2010;36(8): 1234-1241.

38. Anzarut A, Olson J, Singh P, Rowe BH, Tredget EE. The effectiveness of pressure garment therapy for the prevention of abnormal scarring after burn injury: a meta-analysis. J Plast Reconstr Aesthet Surg. 2009;62(1):77-84.

39. Bran GM, Brom J, Hormann K, Stuck BA. Auricular keloids: combined therapy with a new pressure device. Arch Facial Plast Surg. 2012;14(1): 20-26.

40. Kadouch DJ, van der Veer WM, Mahdavian Delavary B, Kerkdijk D, Niessen FB. Therapeutic hotline: An alternative adjuvant treatment after ear keloid excision using a custom-made methyl methacrylate stent. Dermatol Ther. 2010;23(6):686-692.

41. Ragoowansi R, Cornes PG, Moss AL, Glees JP. Treatment of keloids by surgical excision and immediate postoperative single-fraction radiotherapy. Plast Reconstr Surg. 2003;111(6):1853-1859.

42. Guix B, Henriquez I, Andres A, Finestres F, Tello JI, Martinez A. Treatment of keloids by high-dose-rate brachytherapy: a seven-year study. Int J Radiat Oncol Biol Phys. 2001;50(1):167-172.

43. Escarmant P, Zimmermann S, Amar A, et al. The treatment of 783 keloid scars by iridium 192 interstitial irradiation after surgical excision. Int $J$ Radiat Oncol Biol Phys. 1993;26(2):245-251.

44. Sallstrom KO, Larson O, Heden P, Eriksson G, Glas JE, Ringborg U. Treatment of keloids with surgical excision and postoperative X-ray radiation. Scand J Plast Reconstr Surg Hand Surg. 1989;23(3):211-215.

45. van de Kar AL, Kreulen M, van Zuijlen PP, Oldenburger F. The results of surgical excision and adjuvant irradiation for therapy-resistant keloids: a prospective clinical outcome study. Plast Reconstr Surg. 2007;119(7):2248-2254.

46. Ogawa R, Mitsuhashi K, Hyakusoku H, Miyashita T. Postoperative electron-beam irradiation therapy for keloids and hypertrophic scars: retrospective study of 147 cases followed for more than 18 months. Plast Reconstr Surg. 2003;111(2):547-555.

47. Apfelberg DB, Maser MR, Lash H, White D, Weston J. Preliminary results of argon and carbon dioxide laser treatment of keloid scars. Lasers Surg Med. 1984;4(3):283-290.

48. Alster T. Laser scar revision: comparison study of 585-nm pulsed dye laser with and without intralesional corticosteroids. Dermatol Surg. 2003;29(1):25-29.

49. Alster TS, Williams CM. Treatment of keloid sternotomy scars with $585 \mathrm{~nm}$ flashlamp-pumped pulsed-dye laser. Lancet. 1995;345(8959): 1198-1200.

50. Dierickx C, Goldman MP, Fitzpatrick RE. Laser treatment of erythematous/hypertrophic and pigmented scars in 26 patients. Plast Reconstr Surg. 1995;95(1):84-92.

51. Akaishi S, Koike S, Dohi T, Kobe K, Hyakusoku H, Ogawa R. Nd:YAG Laser treatment of keloids and hypertrophic scars. Eplasty. 2012;12:e1.

52. Tanzi EL, Alster TS. Laser treatment of scars. Skin Therapy Lett. 2004;9(1):4-7.

53. Alster TS, Handrick C. Laser treatment of hypertrophic scars, keloids, and striae. Semin Cutan Med Surg. 2000;19(4):287-292.

54. Paquet P, Hermanns JF, Pierard GE. Effect of the $585 \mathrm{~nm}$ flashlamppumped pulsed dye laser for the treatment of keloids. Dermatol Surg. 2001;27(2):171-174.

55. Allison KP, Kiernan MN, Waters RA, Clement RM. Pulsed dye laser treatment of burn scars. Alleviation or irritation? Burns. 2003;29(3): 207-213.

56. Wittenberg GP, Fabian BG, Bogomilsky JL, et al. Prospective, singleblind, randomized, controlled study to assess the efficacy of the 585-nm flashlamp-pumped pulsed-dye laser and silicone gel sheeting in hypertrophic scar treatment. Arch Dermatol. 1999;135(9):1049-1055. 
57. Durani P, Bayat A. Levels of evidence for the treatment of keloid disease. J Plast Reconstr Aesthet Surg. 2008;61(1):4-17.

58. Shih PY, Chen HH, Chen CH, Hong HS, Yang CH. Rapid recurrence of keloid after pulse dye laser treatment. Dermatol Surg. 2008;34(8): $1124-1127$.

59. Cho SB, Lee JH, Lee SH, Lee SJ, Bang D, Oh SH. Efficacy and safety of 1064-nm Q-switched Nd:YAG laser with low fluence for keloids and hypertrophic scars. J Eur Acad Dermatol Venereol. 2010;24(9): 1070-1074.

60. Garg GA, Sao PP, Khopkar US. Effect of carbon dioxide laser ablation followed by intralesional steroids on keloids. J Cutan Aesthet Surg. 2011;4(1):2-6.

61. Sawada Y, Sone K. Hydration and occlusion treatment for hypertrophic scars and keloids. Br J Plast Surg. 1992;45(8):599-603.

62. Fulton JE Jr. Silicone gel sheeting for the prevention and management of evolving hypertrophic and keloid scars. Dermatol Surg. 1995;21(11): 947-951.

63. Ahn ST, Monafo WW, Mustoe TA. Topical silicone gel: a new treatment for hypertrophic scars. Surgery. 1989;106(4):781-786; discussion 786-787.

64. Carney SA, Cason CG, Gowar JP, et al. Cica-Care gel sheeting in the management of hypertrophic scarring. Burns. 1994;20(2):163-167.

65. Lee SM, Ngim CK, Chan YY, Ho MJ. A comparison of Sil-K and Epiderm in scar management. Burns. 1996;22(6):483-487.

66. Mustoe TA. Evolution of silicone therapy and mechanism of action in scar management. Aesthetic Plast Surg. 2008;32(1):82-92.

67. O'Brien L, Pandit A. Silicon gel sheeting for preventing and treating hypertrophic and keloid scars. Cochrane Database Syst Rev. 2006;1: CD003826.

68. Bianchi FA, Roccia F, Fiorini P, Berrone S. Use of Patient and Observer Scar Assessment Scale for evaluation of facial scars treated with selfdrying silicone gel. J Craniofac Surg. 2010;21(3):719-723.

69. van der Wal MB, van Zuijlen PP, van de Ven P, Middelkoop E. Topical silicone gel versus placebo in promoting the maturation of burn scars: a randomized controlled trial. Plast Reconstr Surg. 2010;126(2): $524-531$.

70. Steinstraesser L, Flak E, Witte B, et al. Pressure garment therapy alone and in combination with silicone for the prevention of hypertrophic scarring: randomized controlled trial with intraindividual comparison. Plast Reconstr Surg. 2011;128(4):306e-313e.

71. Chernoff WG, Cramer H, Su-Huang S. The efficacy of topical silicone gel elastomers in the treatment of hypertrophic scars, keloid scars, and post-laser exfoliation erythema. Aesthetic Plast Surg. 2007;31(5):495-500.

72. Stoffels I, Wolter TP, Sailer AM, Pallua N. [The impact of silicone spray on scar formation. A single-center placebo-controlled double-blind trial.] Hautarzt. 2010;61(4):332-338. German.

73. Fitzpatrick RE. Treatment of inflamed hypertrophic scars using intralesional 5-FU. Dermatol Surg. 1999;25(3):224-232.

74. Nanda S, Reddy BS. Intralesional 5-fluorouracil as a treatment modality of keloids. Dermatol Surg. 2004;30(1):54-57.

75. Liu W, Wu X, Gao Z, Song N. Remodelling of keloid tissue into normal-looking skin. J Plast Reconstr Aesthet Surg. 2008;61(12): $1553-1554$.

76. Wu XL, Liu W, Cao YL. Clinical study on keloid treatment with intralesional injection of low concentration 5-fluorouracil. Zhonghua Zheng Xing Wai Ke Za Zhi. 2006;22(1):44-46. Chinese.

77. Wu XL, Gao Z, Song N, Liu W. [Clinical study of auricular keloid treatment wtih both surgical excision and intralesional injection of low-dose 5-fluorouracil and corticosteroids.] Zhonghua Yi Xue Za Zhi. 2009;28(89):1102-1105. Chinese.

78. Asilian A, Darougheh A, Shariati F. New combination of triamcinolone, 5-fluorouracil, and pulsed-dye laser for treatment of keloid and hypertrophic scars. Dermatol Surg. 2006;32(7):907-915.

79. Darougheh A, Asilian A, Shariati F. Intralesional triamcinolone alone or in combination with 5-fluorouracil for the treatment of keloid and hypertrophic scars. Clin Exp Dermatol. 2009;34(2):219-223.
80. Davison SP, Dayan JH, Clemens MW, Sonni S, Wang A, Crane A. Efficacy of intralesional 5-fluorouracil and triamcinolone in the treatment of keloids. Aesthet Surg J. 2009;29(1):40-46.

81. Phan TT, Lim IJ, Sun L, et al. Quercetin inhibits fibronectin production by keloid-derived fibroblasts. Implication for the treatment of excessive scars. J Dermatol Sci. 2003;33(3):192-194.

82. Phan TT, Lim IJ, Chan SY, Tan EK, Lee ST, Longaker MT. Suppression of transforming growth factor beta/smad signaling in keloid-derived fibroblasts by quercetin: implications for the treatment of excessive scars. J Trauma. 2004;57(5):1032-1037.

83. Maragakis M, Willital GH, Michel G, Gortelmeyer R. Possibilities of scar treatment after thoracic surgery. Drugs Exp Clin Res. 1995;21(5): 199-206.

84. Chanprapaph K, Tanrattanakorn S, Wattanakrai P, Wongkitisophon P, Vachiramon V. Effectiveness of onion extract gel on surgical scars in Asians. Dermatol Res Pract. 2012;2012:212945.

85. Jackson BA, Shelton AJ. Pilot study evaluating topical onion extract as treatment for postsurgical scars. Dermatol Surg. 1999;25(4):267-269.

86. Chung VQ, Kelley L, Marra D, Jiang SB. Onion extract gel versus petrolatum emollient on new surgical scars: prospective double-blinded study. Dermatol Surg. 2006;32(2):193-197.

87. Beuth J, Hunzelmann N, Van Leendert R, Basten R, Noehle M, Schneider B. Safety and efficacy of local administration of contractubex to hypertrophic scars in comparison to corticosteroid treatment. Results of a multicenter, comparative epidemiological cohort study in Germany. In Vivo. 2006;20(2):277-283.

88. Ho WS, Ying SY, Chan PC, Chan HH. Use of onion extract, heparin, allantoin gel in prevention of scarring in chinese patients having laser removal of tattoos: a prospective randomized controlled trial. Dermatol Surg. 2006;32(7):891-896.

89. Koc E, Arca E, Surucu B, Kurumlu Z. An open, randomized, controlled, comparative study of the combined effect of intralesional triamcinolone acetonide and onion extract gel and intralesional triamcinolone acetonide alone in the treatment of hypertrophic scars and keloids. Dermatol Surg. 2008;34(11):1507-1514.

90. Har-Shai Y, Sabo E, Rohde E, Hyams M, Assaf C, Zouboulis CC. Intralesional cryosurgery enhances the involution of recalcitrant auricular keloids: a new clinical approach supported by experimental studies. Wound Repair Regen. 2006;14(1):18-27.

91. Har-Shai Y, Amar M, Sabo E. Intralesional cryotherapy for enhancing the involution of hypertrophic scars and keloids. Plast Reconstr Surg. 2003;111(6):1841-1852.

92. Har-Shai Y, Brown W, Labbe D, et al. Intralesional cryosurgery for the treatment of hypertrophic scars and keloids following aesthetic surgery: the results of a prospective observational study. Int $J$ Low Extrem Wounds. 2008;7(3):169-175.

93. Tziotzios C, Profyris C, Sterling J. Cutaneous scarring: pathophysiology, molecular mechanisms, and scar reduction therapeutics Part II. Strategies to reduce scar formation after dermatologic procedures. $J \mathrm{Am}$ Acad Dermatol. 2012;66(1):13-24; quiz 25-26.

94. Zurada JM, Kriegel D, Davis IC. Topical treatments for hypertrophic scars. J Am Acad Dermatol. 2006;55(6):1024-1031.

95. Berman B, Kaufman J. Pilot study of the effect of postoperative imiquimod $5 \%$ cream on the recurrence rate of excised keloids. J Am Acad Dermatol. 2002;47(Suppl 4):S209-S211.

96. Chuangsuwanich A, Gunjittisomram S. The efficacy of 5\% imiquimod cream in the prevention of recurrence of excised keloids. J Med Assoc Thai. 2007;90(7):1363-1367.

97. Martin-Garcia RF. Imiquimod: an effective alternative for the treatment of invasive cutaneous squamous cell carcinoma. Dermatol Surg. 2005;31(3):371-374.

98. Stashower ME. Successful treatment of earlobe keloids with imiquimod after tangential shave excision. Dermatol Surg. 2006;32(3):380-386.

99. Berman B, Harrison-Balestra C, Perez OA, et al. Treatment of keloid scars post-shave excision with imiquimod $5 \%$ cream: a prospective, double-blind, placebo-controlled pilot study. J Drugs Dermatol. 2009;8(5):455-458. 
100. Cacao FM, Tanaka V, Messina MC. Failure of imiquimod 5\% cream to prevent recurrence of surgically excised trunk keloids. Dermatol Surg. 2009;35(4):629-633.

101. Espana A, Solano T, Quintanilla E. Bleomycin in the treatment of keloids and hypertrophic scars by multiple needle punctures. Dermatol Surg. 2001;27(1):23-27.

102. Naeini FF, Najafian J, Ahmadpour K. Bleomycin tattooing as a promising therapeutic modality in large keloids and hypertrophic scars. Dermatol Surg. 2006;32(8):1023-1030.

103. Saray Y, Gulec AT. Treatment of keloids and hypertrophic scars with dermojet injections of bleomycin: a preliminary study. Int J Dermatol. 2005;44(9):777-784.

104. Jimenez SA, Freundlich B, Rosenbloom J. Selective inhibition of human diploid fibroblast collagen synthesis by interferons. J Clin Invest. 1984;74(3):1112-1116.

105. Berman B, Duncan MR. Short-term keloid treatment in vivo with human interferon alfa-2b results in a selective and persistent normalization of keloidal fibroblast collagen, glycosaminoglycan, and collagenase production in vitro. J Am Acad Dermatol. 1989;21(4 Pt 1): 694-702.

106. Tredget EE, Shankowsky HA, Pannu R, et al. Transforming growth factor-beta in thermally injured patients with hypertrophic scars: effects of interferon alpha-2b. Plast Reconstr Surg. 1998;102(5):1317-1328; discussion 1329-1330.

107. Viera MH, Amini S, Valins W, Berman B. Innovative therapies in the treatment of keloids and hypertrophic scars. J Clin Aesthet Dermatol. 2010;3(5):20-26.

108. Lee BJ, Jeong JH, Wang SG, Lee JC, Goh EK, Kim HW. Effect of botulinum toxin type a on a rat surgical wound model. Clin Exp Otorhinolaryngol. 2009;2(1):20-27.

109. Gassner HG, Brissett AE, Otley CC, et al. Botulinum toxin to improve facial wound healing: a prospective, blinded, placebo-controlled study. Mayo Clin Proc. 2006;81(8):1023-1028.
110. Zhibo X, Miaobo Z. Intralesional botulinum toxin type A injection as a new treatment measure for keloids. Plast Reconstr Surg. 2009;124(5): $275 \mathrm{e}-277 \mathrm{e}$.

111. Xiao Z, Zhang F, Lin W, Zhang M, Liu Y. Effect of botulinum toxin type A on transforming growth factor betal in fibroblasts derived from hypertrophic scar: a preliminary report. Aesthetic Plast Surg. 2010;34(4):424-427.

112. Gauglitz GG, Bureik D, Dombrowski Y, Pavicic T, Ruzicka T, Schauber J. Botulinum toxin A for the treatment of keloids. Skin Pharmacol Physiol. 2012;25(6):313-318.

113. Karrrer S, BosserhoffAK, Weiderer P, et al. Influence of 5-aminolevulinic acid and red light on collagen metabolism of human dermal fibroblasts. J Invest Dermatol. 2003;120:325-331.

114. Heckenkamp J, Aleksic M, Gawenda M, et al. Modulation of human adventitial fibroblast function by photodynamic therapy of collagen matrix. Eur J Vasc Endovasc Surg. 2004;28:651-659.

115. Ud-Din S, Thomas G, Morris J, et al. Photodynamic therapy: an innovative approach to the treatment of keloid disease evaluated using subjective and objective non-invasive tools. Arch Dermatol Res. Epub November 2, 2012.

116. Ferguson MW, Duncan J, Bond J, et al. Prophylactic administration of avotermin for improvement of skin scarring: three double-blind, placebo-controlled, phase I/II studies. Lancet. 11, 2009;373(9671): 1264-1274.

117. thepharmaletter.com [homepage on the Internet]. Available from: http:// www.thepharmaletter.com. Accessed March 24, 2013.

118. Har-Shai Y. Intralesional cryosurgery for enhancing the involution of hypertrophic scars and keloids. A new effective technology based on experimental and clinical data. Journal of Wound Technology. 2012;15:8-9.
Clinical, Cosmetic and Investigational Dermatology

\section{Publish your work in this journal}

Clinical, Cosmetic and Investigational Dermatology is an international, peer-reviewed, open access, online journal that focuses on the latest clinical and experimental research in all aspects of skin disease and cosmetic interventions. All areas of dermatology will be covered; contributions will be welcomed from all clinicians and

\section{Dovepress}

basic science researchers globally. This journal is indexed on CAS The manuscript management system is completely online and includes a very quick and fair peer-review system, which is all easy to use. Visit http://www.dovepress.com/testimonials.php to read real quotes from published authors. 